\title{
Pathogenesis, Clinical Signs and Treatment Recommendations in Brittle Nails: A Review
}

\author{
Marco A. Chessa (1) - Matilde Iorizzo - Bertrand Richert · \\ Jose L. López-Estebaranz · Dimitrios Rigopoulos · Antonella Tosti · \\ Aditya K. Gupta · Nilton Di Chiacchio · Nilton G. Di Chiacchio • \\ Adam I. Rubin · Robert Baran · Shari R. Lipner · Ralph Daniel • \\ Soumya Chiheb $\cdot$ Chander Grover $\cdot$ Michela Starace $\cdot$ Bianca M. Piraccini
}

Received: September 10, 2019 / Published online: November 20, 2019

(C) The Author(s) 2019, corrected publication 2020

\section{ABSTRACT}

Nail plate brittleness (or fragility) is a common complaint affecting up to $20 \%$ of the population, especially women over 50 years of age, with fingernail fragility being more prevalent than toenail fragility. Nail brittleness is characterized by nails that split, flake and crumble, become soft and lose elasticity. The main clinical presentations are: onychoschizia, onychorrhexis, superficial granulation of keratin and worn-down nails. According to causative factors, we can distinguish 2 forms of nail fragility

Enhanced Digital Features To view enhanced digital features for this article go to https://doi.org/10.6084/ m9.figshare.10011824.

M. A. Chessa $(\bowtie) \cdot$ M. Starace - B. M. Piraccini Dermatology Unit, Department of Experimental, Diagnostic and Specialty Medicine, University of Bologna, Bologna, Italy

e-mail: marcoadriano.chessa@gmail.com

M. Iorizzo

Private Dermatology Practice, Bellinzona/Lugano, Switzerland

B. Richert

Saint Pierre - Brugmann and Queen Fabiola Children's University Hospitals, Université Libre de Bruxelles, Brussels, Belgium

J. L. López-Estebaranz

University Fundación Alcorcón Hospital, Madrid, Spain
(NF): a primary "idiopathic or brittle nail syndrome" form and NF secondary to different causes such as inflammatory nail disorders, infections, systemic diseases and general conditions, traumas and alteration of the nail hydration. Optimal management requires treatment of the primary cause of brittle nails, when possible. In idiopathic NF oral supplementation, vitamins (especially biotin, also known as vitamin B7), trace elements and amino acids (especially cysteine) have been reported to be useful. In addition, several products, such as topical moisturizers and lacquers could be considered to restructure the affected nail plate and to reduce psychological impacts of this common problem.

\section{Rigopoulos}

Department of Dermatology, National and Kapodistrian University of Athens, "A. Sygros" Hospital, Athens, Greece

\section{A. Tosti}

Department of Dermatology and Cutaneous Surgery, Miller School of Medicine, University of Miami, Miami, FL, USA

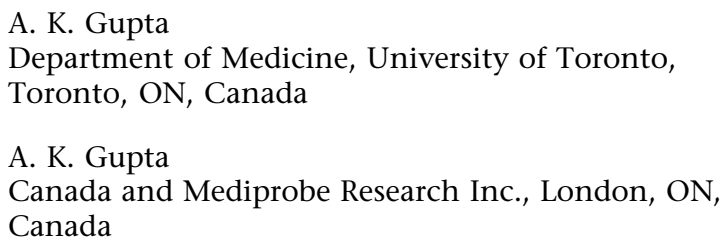


Keywords: Aging;

Onychoschizia;

Onychorrhexis; Nail brittleness; Nail cosmetic; Nail fragility

\section{Key Summary Points}

Why carry out this study?

This review explores and updates the topic of brittle nails, a common condition and a frequent cause of dermatological consultation, providing comprehensive details about clinical presentation, pathophysiology and treatment options.

What was learned from the study?

Optimal management of brittle nails requires treatment of the primary cause, when present, added to protective measures and bio-mineral supplementation. In addition, several topical products could be considered to improve nail plate fragility and reduce the physical and psychological impacts of this common problem.

\section{INTRODUCTION}

Nail plate (NP) brittleness (or fragility) is a common complaint affecting up to $20 \%$ of the population, especially women over 50 years of

N. Di Chiacchio - N. G. Di Chiacchio Dermatology Clinic - Hospital do Servidor Público Municipal de São Paulo, São Paulo, Brazil

N. G. Di Chiacchio

Dermatology Discipline - Faculade de Medicina do ABC, Santo André, Brazil

\section{A. I. Rubin}

Department of Dermatology, Hospital of the

University of Pennsylvania, and Section of

Dermatology, Children's Hospital of Philadelphia, Perelman School of Medicine at the University of Pennsylvania, Philadelphia, PA, USA

R. Baran

Nail Disease Center, Cannes, France age, with fingernail fragility being more prevalent than a toenail fragility [1].

Nail brittleness is characterized by nails that split, flake and crumble, become soft and lose elasticity. The main clinical presentations of brittle nails $(\mathrm{BN})$ that have been described are: onychoschizia, onychorrhexis, superficial granulation of keratin and worn-down nails. Different signs of nail brittleness (NB) can be present alone, together in the same patient and together in the same nail plate. BN are generally not painful, but affected patients often complain of significant cosmetic and functional problems such as impairment in performing daily or occupational activities [2]. Pain may occur from deep splitting and catching everything. In a cross-sectional study, the perception of $\mathrm{BN}$ was even associated with a depressed mood [3].

This review explores and updates the topic of $\mathrm{BN}$, providing comprehensive details about clinical presentation, pathophysiology and treatment options.

\section{METHODS}

\section{Data Source and Search Strategy}

We collected all studies related to BN indexed in PubMed from its inception to 31 August 2019. Search parameters included the following words or sentences: "brittle nails", "nail fragility", "etiology of brittle nails", "onychoschizia", "onychorrhexis", "worn down nails", "keratin granulation", "therapy of brittle nails" and "treatment of brittle nails". Only articles in

S. R. Lipner

Department of Dermatology, Weill Cornell

Medicine, New York, NY, USA

R. Daniel

University of Mississippi, Medical Center, University of Alabama, Birmingham, AL, USA

S. Chiheb

Faculty of Medicine and Pharmacy, University

Hassan II, Casablanca, Morocco

C. Grover

University College of Medical Sciences and Guru

Teg Bahadur Hospital, Delhi, India 
English were included. All papers included in this study involved human or animal clinical studies, including case reports, case series and reviews. A subsequent review of the respective reference sections of the articles aimed to identify any undetected reports.

This article is based on previously conducted studies and does not contain any studies with human participants or animals performed by any of the authors.

The objective of this search was to analyze and document a review of the literature to propose some guidelines for the treatment of this disease.

\section{BRITTLE NAILS}

$\mathrm{BN}$ may be a consequence of factors that alter nail plate production and/or factors that damage the NP.

Under physiologic conditions the NP is a fully keratinized structure made up of about 25 layers of tightly packed keratinocytes, with a thickness of $0.5-1 \mathrm{~mm}$ and a smooth surface. The majority of the NP derives from the proximal nail matrix (NM) and around $1 / 3$ by the distal matrix and bed. The NM is localized under the proximal nail fold. Epithelial growth and keratinization of NM keratinocytes follow an oblique axis; during this process of maturation and differentiation cells move upward and distally. Normal nail growth is highly dependent on vascularization and inflammation $[4,5]$. Impairment of this process results in NP abnormalities.

The clinical aspects of NB due to NM damage can vary depending on the site and the extent of the injury. NP thinning due to proximal NM damage always involves the whole nail length and is often associated with abnormalities in the superficial NP. Damage to the distal matrix, on the other hand, may produce alterations in the shape of the NP free edge, but not of the superficial NP.

BN may be caused by several factors: first of all, a physiological increased nail fragility is typical of aging. Other local or systemic causes include inflammatory nail diseases, onychomycosis, systemic conditions, medication ingestion, and trauma (occupational and professional). When a secondary cause has not been identified, the disease is defined as idiopathic.

Clinically, three main clinical aspects of NF have been described:

1. Onychorrhexis: particularly frequent among middle-age women and characterized by longitudinal splitting and shallow parallel furrows running on the superficial layer of the nail (Fig. 1). The severity of the clinical presentation depends on the degree of the causative factor on the NM. Longitudinal ridges may vary from a few superficial ridges up to deep furrows, affecting from a small part of the nail surface to at least 70\% of the total nail surface. Likewise, longitudinal splitting may vary from a few superficial splits up to multiple deep fissures. A single longitudinal split of the entire NP is sometimes observed (split nail) (Fig. 2). The pain induced by the deep splits may be the cause for medical advice being sought.

2. Lamellar onychoschizia: caused by the impairment of intercellular adhesive factors of the NP. As a result, the NP exfoliates into fine horizontal layers (Fig. 3). Nail hardness is mainly secondary to high sulphur amino acids, particularly cystine, and tight keratin cross-links. The keratin protein in nails is hardest at a slightly acid $\mathrm{pH}$. Adhesion between cells is facilitated by membranecoating granules with linkage by lipids, such as acyl ceramides. Triangular pieces of NP may easily be torn off from the free margin (crenellated splitting). In other cases, breaking of the lateral edges could cause transverse splitting. This type of nail fragility is almost exclusive to fingernails and it is typical of patients who wash their hands too frequently (e.g., homemakers, but also doctors and nurses). Proximal lamellar splitting may occasionally be observed in lichen planus or during etretinate or acitretin therapy.

3. Superficial granulation of keratin is a brittleness confined to the dorsal NP, not to be confused with superficial white onychomycosis. Superficial granulation of 


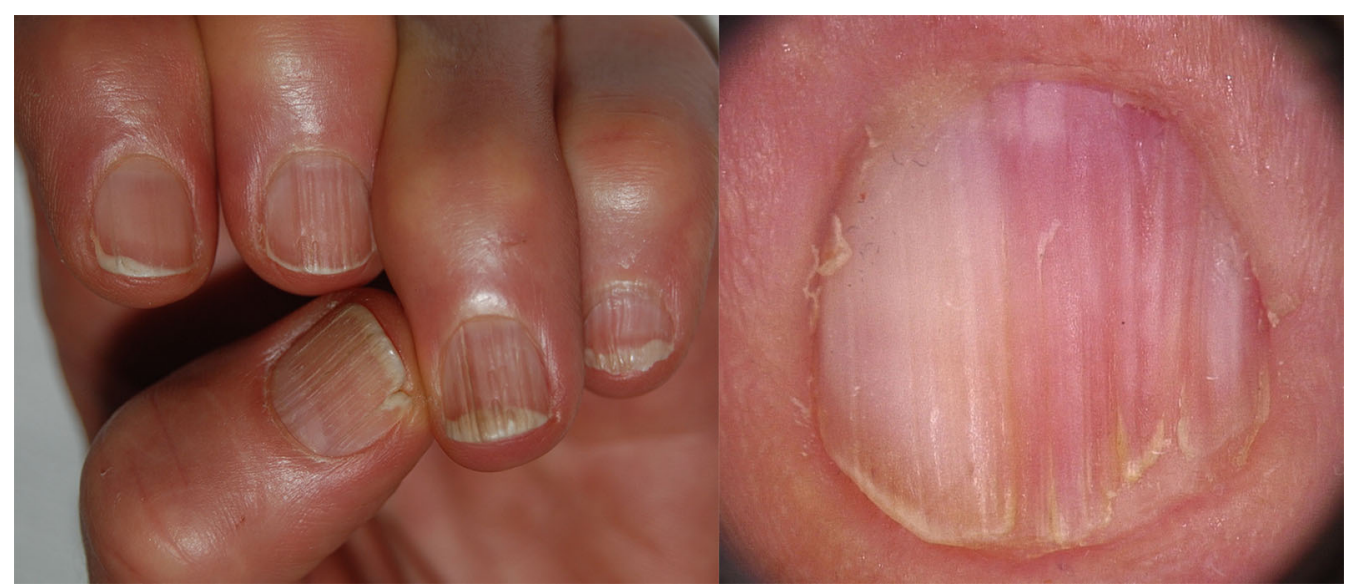

Fig. 1 Onychorrhexis: several longitudinal parallel furrows and thin fissures running on the superficial layer of the nail

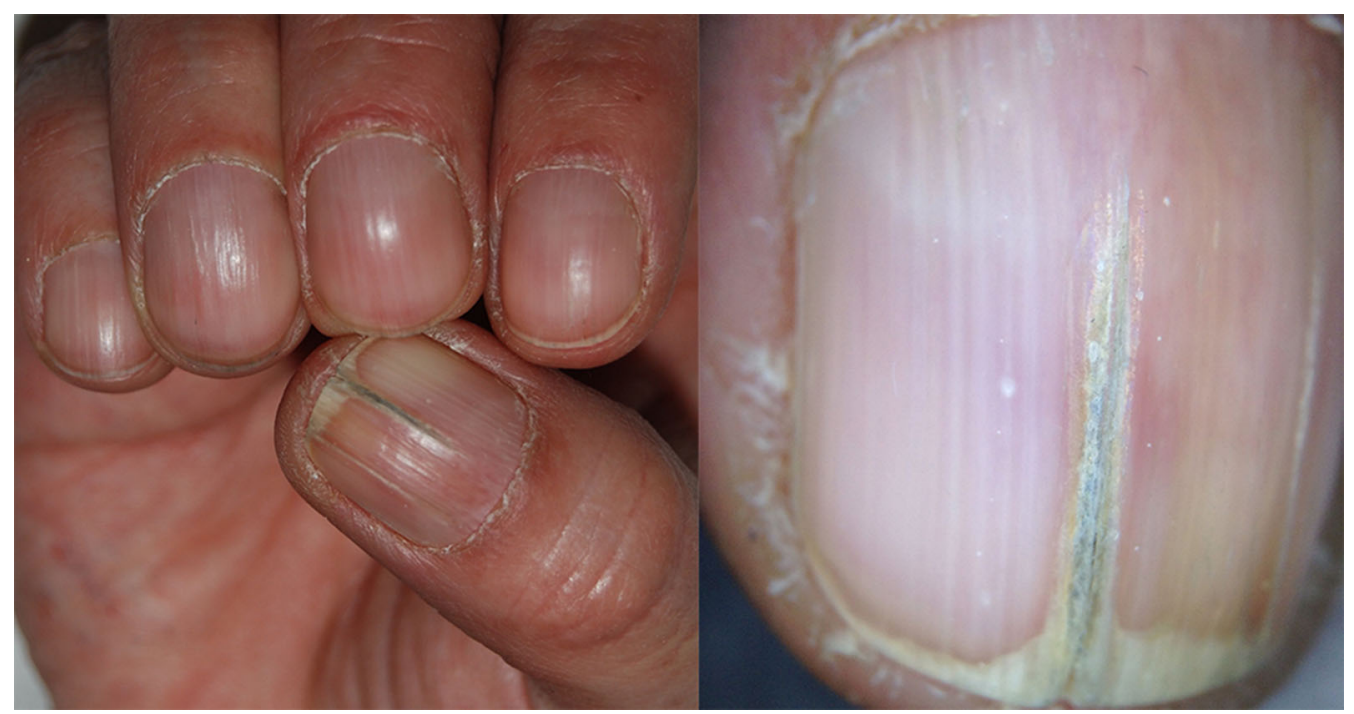

Fig. 2 Onychorrhexis presenting as single longitudinal split of nail plate

keratin is often reported in patients wearing nail polish for months, sometimes applying it over the previous coating. In this way NP keratins undergo to a gradual 'granulation' or exfoliation with the formation of small white-yellow patches and striations (Fig. 4). Keratin degranulation is a type of pseudoleukonychia, where the white discoloration of the nail is due to white particles (the damaged onychocytes) on the NP surface.

According to causative factors, we can distinguish 2 forms of NF: a primary "idiopathic" form and NF secondary to different causes.

\section{Idiopathic Nail Brittleness (Brittle Nail Syndrome)}

This is the most common cause of NB, almost exclusively seen in the fingernails. In women, the intercellular keratinocyte bridges are constitutionally weaker than in males and this can be considered a cause of the higher frequency of this complaint among females. Moreover, normal nails contain 5\% lipids and there is a decrease in cholesterol sulphate of the NP with age, especially in post-menopausal women, suggesting an important role of lipids in the development of NB [6]. Some authors have identified reduced water content in the nail 


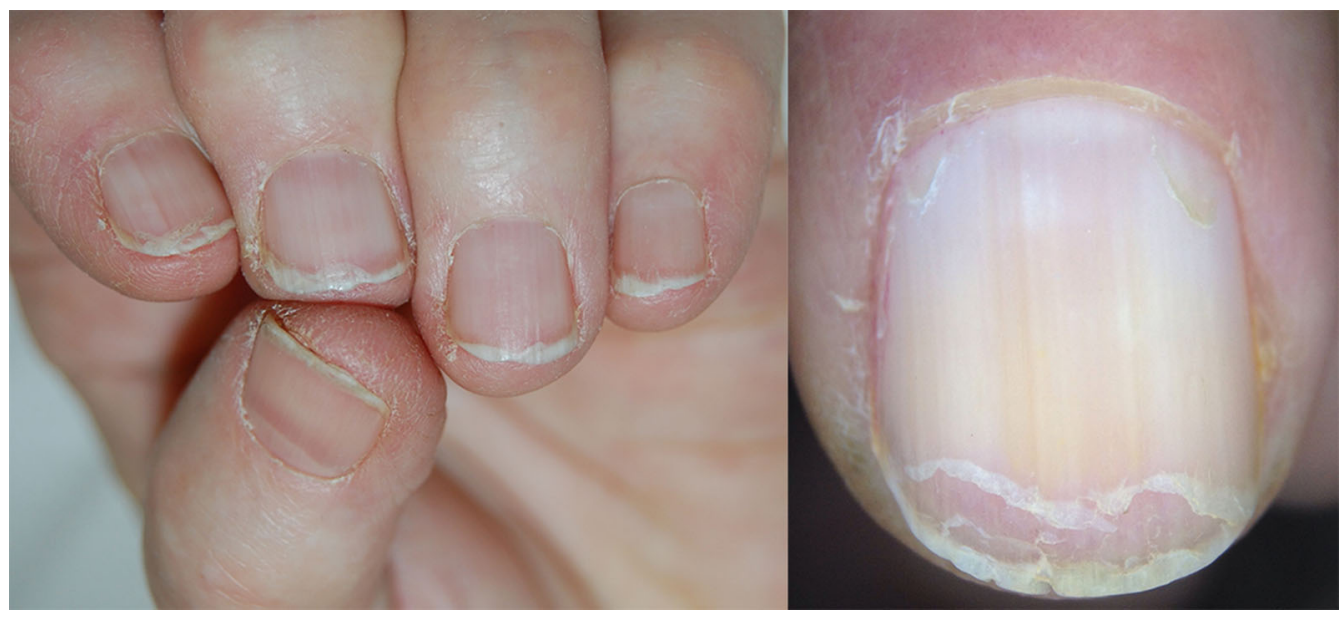

Fig. 3 Lamellar onychoschizia: the free margin of the nail splits in horizontal layers

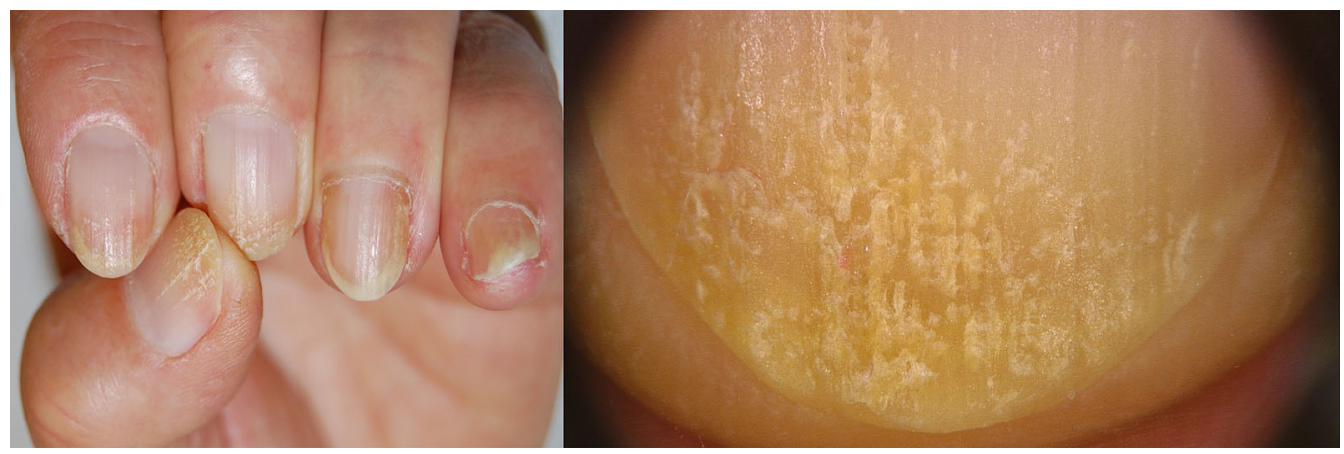

Fig. 4 Superficial granulation of keratin: the distal nail plate shows opaque white and fragile patches and striations

plate $(<16 \%)$ as a possible cause of $\mathrm{BN}[5]$. In contrast, other studies found no significant difference in water content of brittle compared with normal nails $[7,8]$.

\section{Secondary Nail Brittleness}

\section{Inflammatory Nail Disorders}

Several dermatoses such as psoriasis, lichen planus, lichen striatus, alopecia areata, Darier's disease and eczema may involve the nail apparatus $[9,10]$. Usually these disorders are diagnosed as separate entities although features of nail fragility are common in these patients.

In fact, up to $50 \%$ of patients affected by psoriasis present nail abnormalities that are frequently associated with NB. When the proximal part of the NM is involved, the NP presents irregular and deep pits (Fig. 5), while a more extensive psoriatic involvement of the NM induces a friable and brittle NP [11].

Lichen planus in its various forms can also affect the nails. About $10 \%$ of patients with lichen planus have specific nail involvement [12]. Depending on the degree of inflammation, the nail changes consist of thinning, longitudinal ridging and splitting of the NP (Fig. 6). Rarely, erosive lichen planus may involve the nails [13]. In lichen striatus, nail involvement is similar to that of lichen planus, but typically only half of the NP is affected [14].

Approximately $2 / 3$ of patients with alopecia areata have nail changes, such as pits secondary to proximal NM involvement, onychorrhexis, thinning and trachyonychia (Fig. 7). Changes may be seen in one, several or all the nails. 


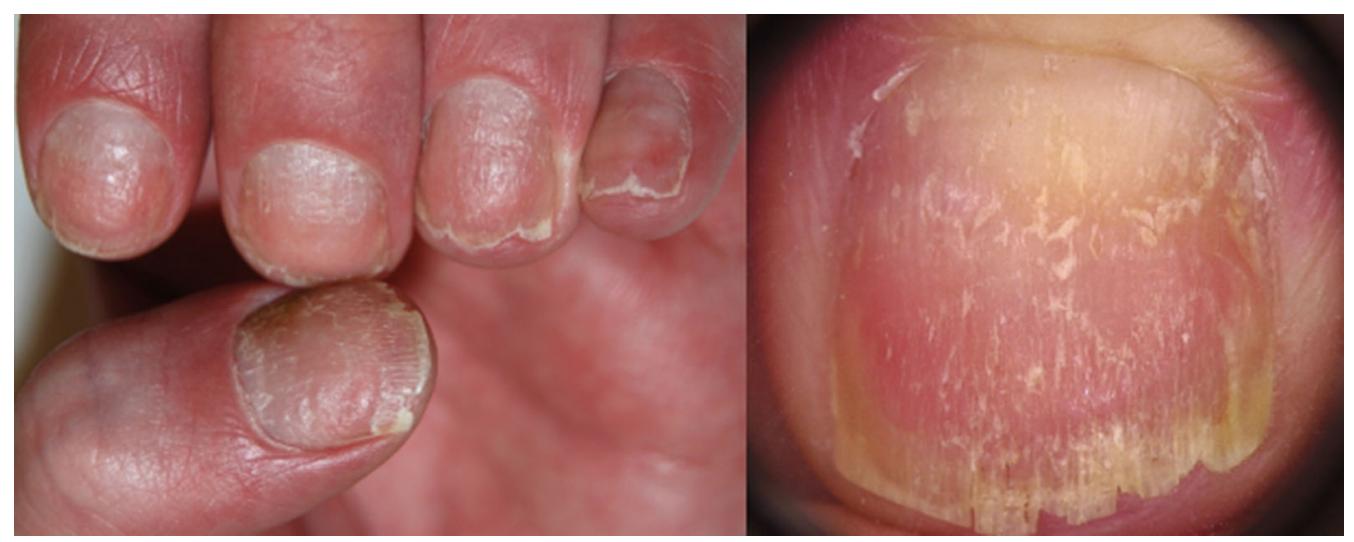

Fig. 5 Nail fragility due to nail matrix psoriasis: irregular pitting and brittle distal margin

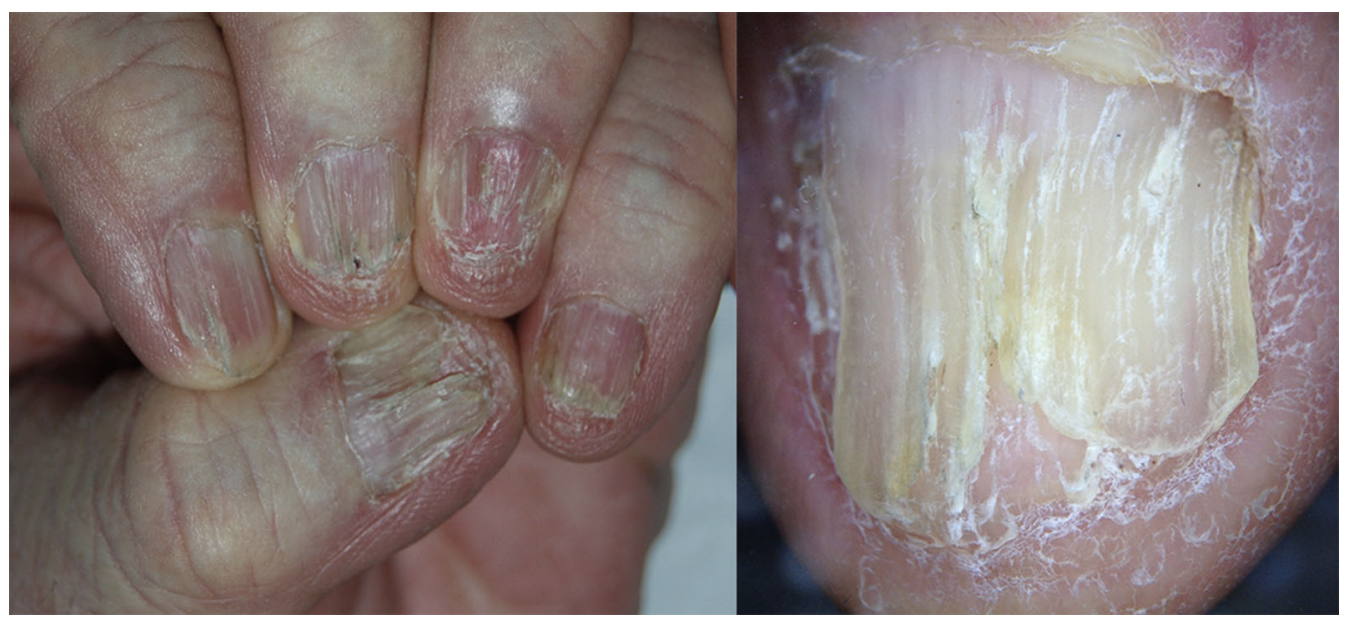

Fig. 6 Nail fragility due to nail lichen planus: nail plate thinning, longitudinal fissuring and splitting of the nail plate

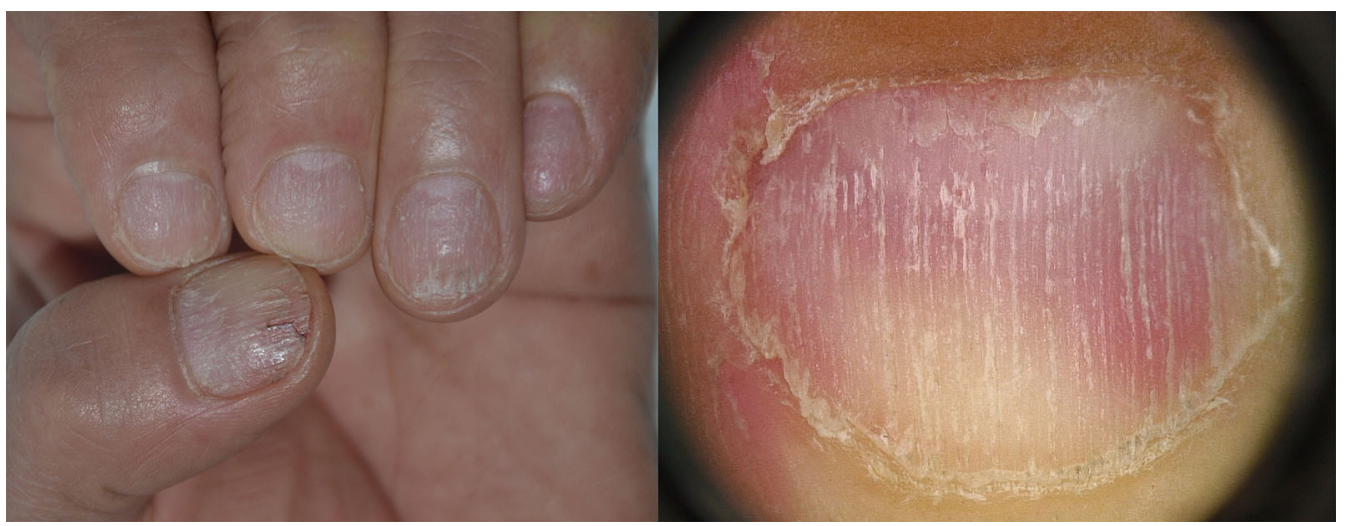

Fig. 7 Nail fragility due to alopecia areata of the nails: with regular thin onychorrhexis leading to trachyonychia

Periungual eczema, seen in contact dermatitis or atopic dermatitis, is frequently associated with NP fragility (Fig. 8).

\section{Infections}

Superficial white onychomycosis is an example of a cause of NF secondary to NP damage. In this 


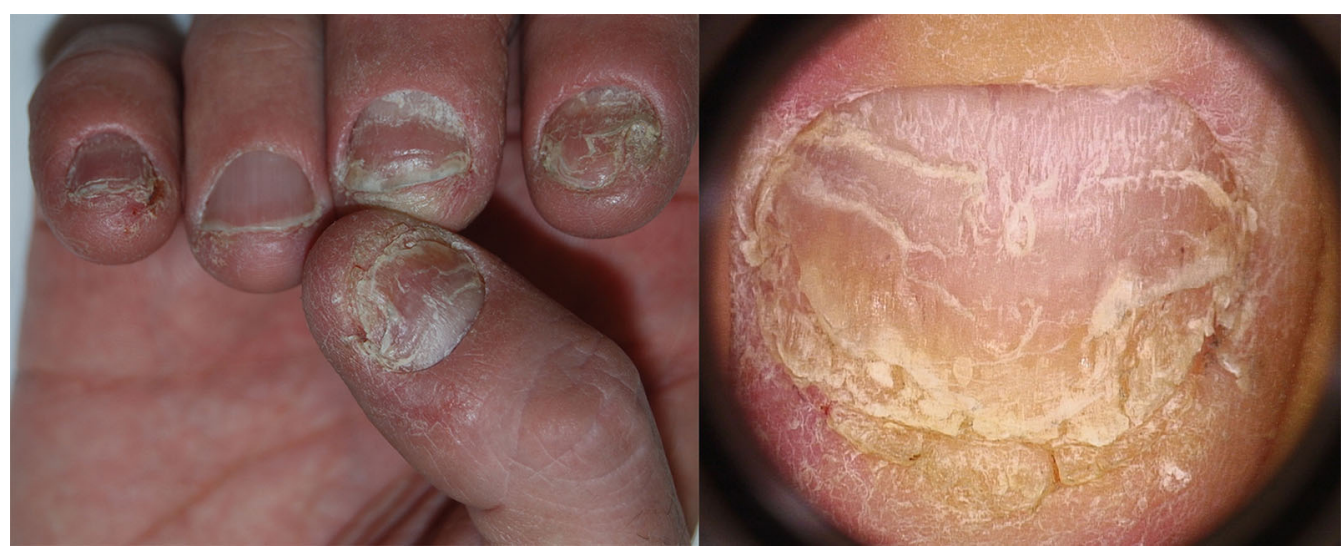

Fig. 8 Nail fragility due to hand eczema: nail plate thinning with diffuse scaling associated with periungual inflammatory signs

type of onychomycosis, the fungal hyphae colonize the most superficial layers of the NP, and it becomes white, opaque, and friable in multiple small spots secondary to keratin digestion by fungi [15] (Fig. 9).

In distal subungual onychomycosis, fungi invade the nail bed from the distal free margin of the NP, inducing NF in the distal portion (Fig. 10).

Several infectious diseases such as syphilis and pulmonary tuberculosis can give nonspecific alterations to the nails such as nail thinning and fissuring of the free margin and an overall fragility $[16,17]$.

\section{Systemic Diseases and General Conditions}

BN have also been linked with systemic diseases, nutritional deficiencies and medication ingestion, but they are often only a non-specific sign that accompanies these conditions $[6,7]$.

The impairment of peripheral circulation secondary to arteriopathy, neurological disorders, chronic anemia and arteriosclerosis may lead to a reduced NM vascularization with production of a thin NP [18].

Patients with endocrine disorders may present with $\mathrm{BN}$, slow nail growth and longitudinal ridging and fissuring. Nail changes, characterized by brittleness and softness, are present in about $5 \%$ of cases of hyperthyroidism and are often reversible following successful therapy.

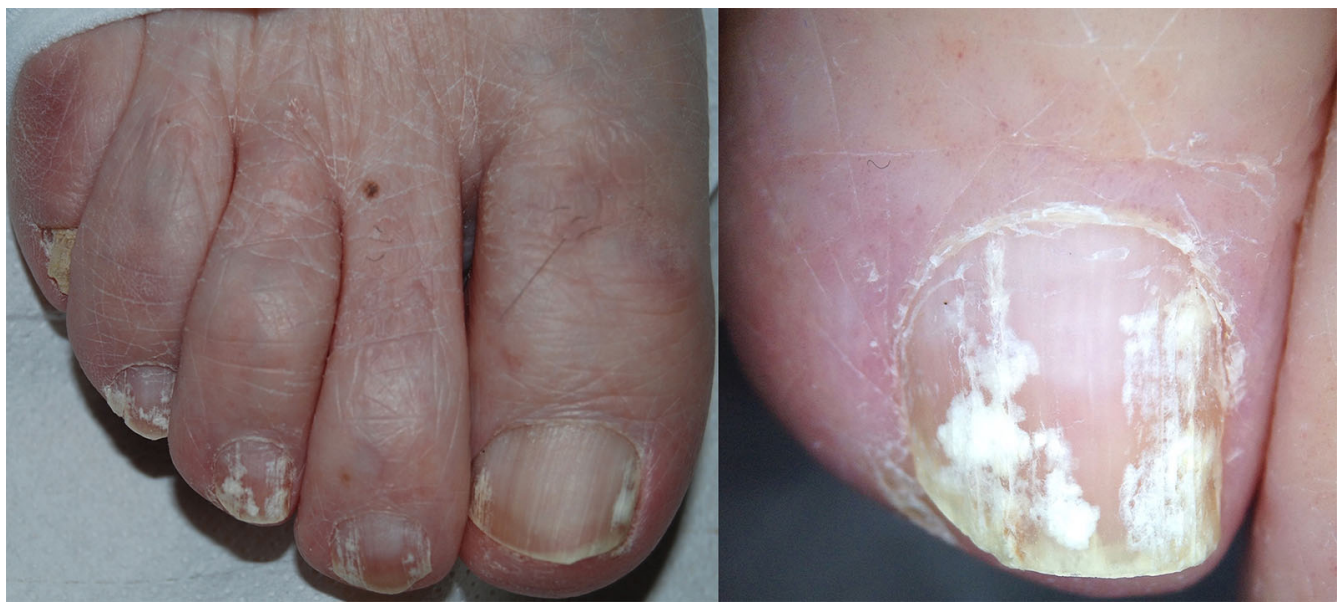

Fig. 9 Nail fragility due to white superficial onychomycosis: multiple white, opaque friable spots on the nail surface 


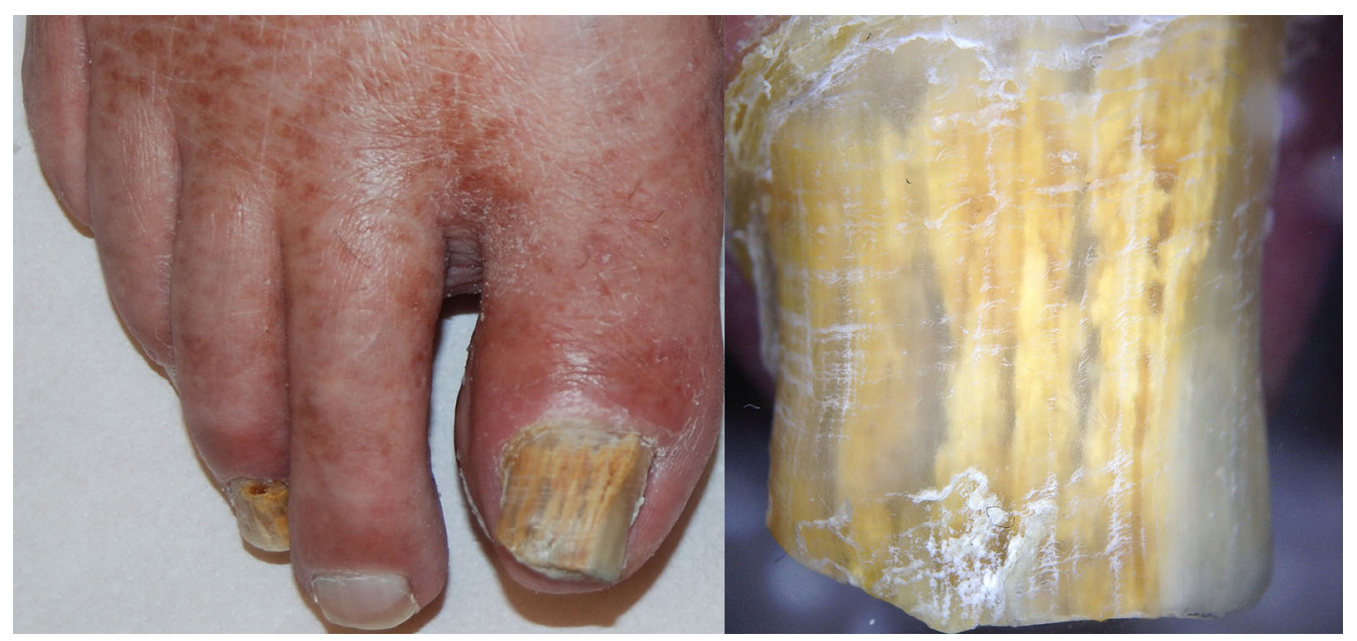

Fig. 10 Nail fragility due to distal subungual onychomycosis: nail surface brittleness is evident in the distal nail

The nails are affected in $90 \%$ of patients with hypothyroidism and typically appear thin, brittle, slow-growing and with longitudinal or transverse striae [19].

Onycholysis, increased fragility, longitudinal ridging and crumbling may occur in amyloidosis.

Systemic medications such as cancer chemotherapeutic agents, retinoids or antiretrovirals may be responsible for lamellar onychoschizia.

A severe deficiency of vitamins, trace elements and aminoacids from daily food intake may result in NF and thinning [20].

\section{Traumas and Alteration of Nail Hydration}

Traumas significantly contribute to damage of the NP and alteration of the NP surface. NF can be caused by mechanical micro-traumas secondary to routine professional activities, as in homemakers, housemaids, shoemakers, ironworkers, and carpenters. Occupational exposure to solvents and solutions (chemical/medical personnel, photographers or painters, for example) can dissolve intercellular lipids and damage intercellular cohesion. Onychotillomania and onychophagia are another two causes of traumatic BN (Fig. 11).

The methods used to prepare nails for cosmesis and all methods of removing the applied preparations damage the healthy nail plates. However, the application of nail polish itself does not cause an alteration of the $\mathrm{pH}$ of the nail lamina, being approximately 5.8 , which is very close to the physiological value [21]. Water is stored above all in the ventral portion of the NP and the alteration of water content of the NP could cause BN (Fig. 12). Dehydration is more rapid if nails are not kept short [22]. Moreover, hydration and desiccation may play a significant role in household employees, hairdressers, and nurses where repeated wetting and drying of the hands leads to fractures between NP onychocytes.

Finally, occlusive gloves applied over wet hands while working may be a cause of $\mathrm{BN}$, leading to splintered, fractured nails and onychoschisis [23].

\section{TREATMENT: FACTS AND CONTROVERSIES}

Secondary NB should be treated by acting, when possible, on the primary cause. In these cases, treatment includes the cure of the dermatological/systemic condition, avoidance of traumas and allergens/irritants, limiting contact with water and detergents, and regular use of emollients [6]. However, most patients consulting for NB have an idiopathic NF. Oral supplementation with vitamins (especially biotin, also known as vitamin B7), trace elements, and amino acids (especially cysteine) have been 


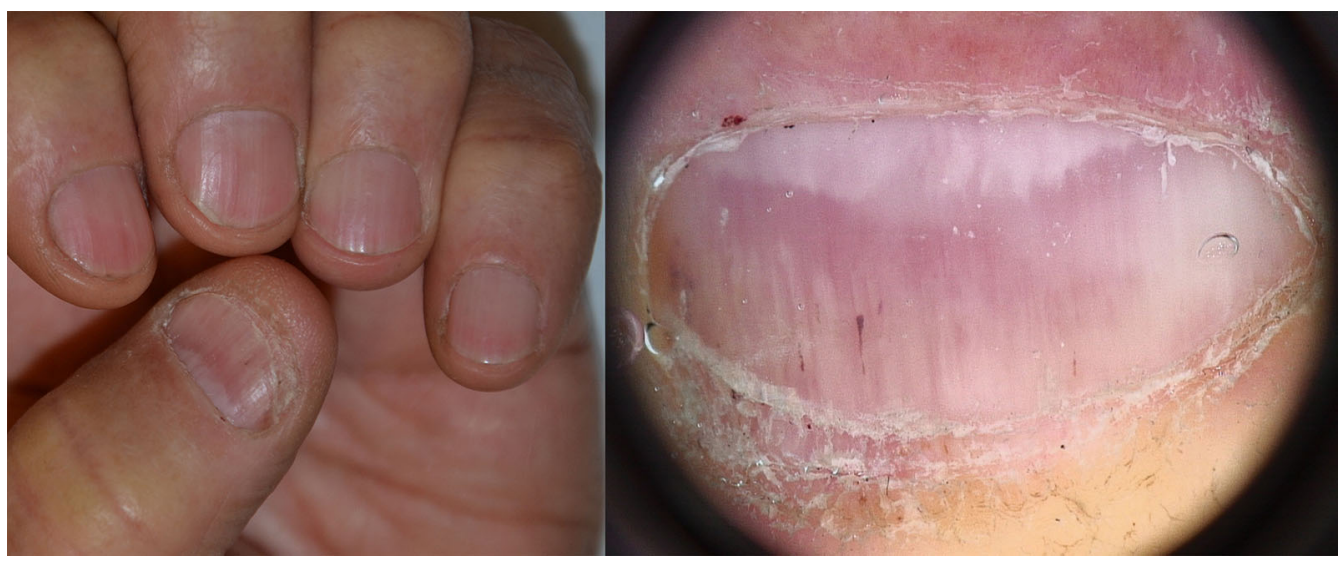

Fig. 11 Nail fragility due to mechanical trauma in onychotillomania: the distal margin of the nail has an irregular fragmented appearance with scaling

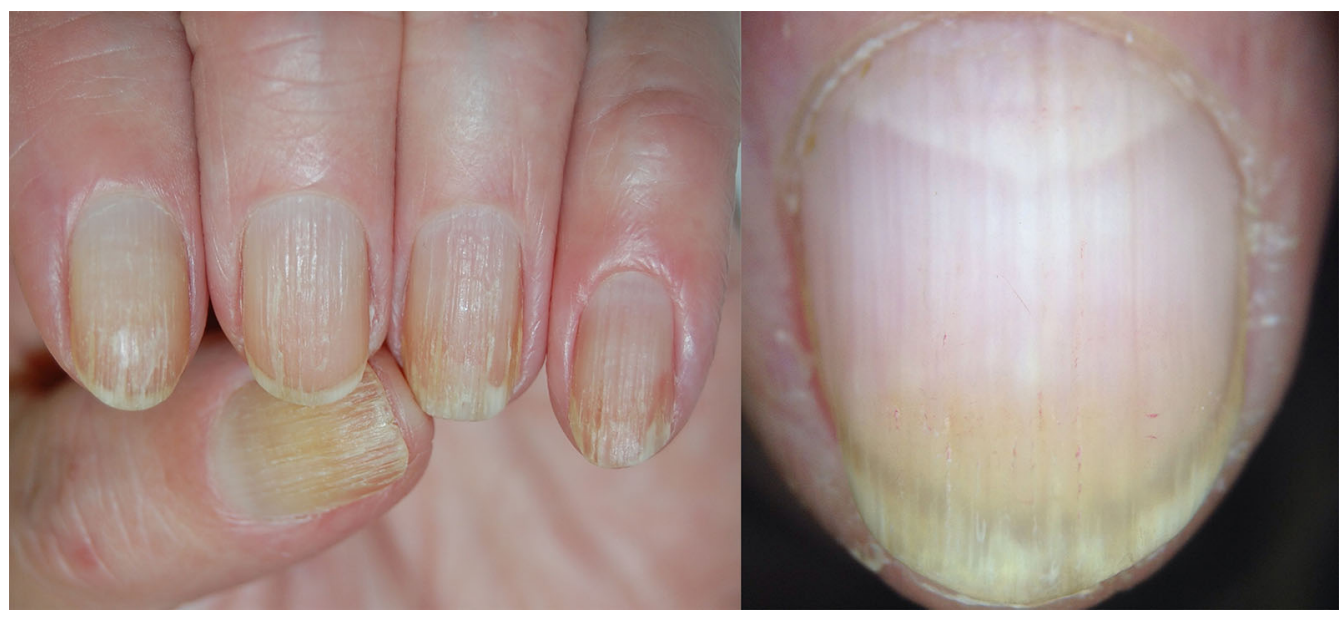

Fig. 12 Nail fragility due to chemical trauma by prolonged use of colored nail lacquer: yellow discoloration and onychorrhexis more marked in the distal nail

reported useful in improving idiopathic fragility [24-26]. However, these studies were small, not well controlled, and one study was retrospective, survey based.

Biotin is a water-soluble vitamin contained in several foods such as cereals, walnuts, peanuts, milk, and egg yolks. This vitamin is also synthetized by intestinal bacteria. Biotin:

- Takes part in keratin biosynthesis and intercellular cement holding keratinocytes together, acting as the prosthetic group of several essential enzymes;

- Improves the ultrastructure of the NP (onychocytes show more regular arrangements and distribution) and its resistance to tension.

Several studies have demonstrated, both with clinical and electron microscopy examinations [27], an improvement of firmness and hardness of the fingernails of patients receiving biotin supplementation [28-30]. A dosage of $5-10 \mathrm{mg}$ a day for $3-6$ months is usually recommended.

High biotin intake (more than $10 \mathrm{mg}$ per day) can cause falsely high or falsely low laboratory test results (FDA safety communication) [31]. Troponins, thyroid, prolactin and pregnancy tests are some of the most frequently 
altered [32-34]. The presence of biotin can interfere with tests that use biotin-streptavidin technology. The interaction between biotin and streptavidin is used as the basis for many biotinbased immunoassays, and these immunoassays are vulnerable to interference when they are used to analyze a sample that contains biotin. The FDA warning on this topic emphasizes that physicians should obtain an updated list of medications, including vitamins and supplements, and doses, at each visit [31]. This is particularly important as patients are not aware of the risks associated with biotin [35].

A combination of an arginine silicate complex and magnesium biotinate (a novel wellabsorbed biotin salt) was demonstrated to increase nail growth [36]. However, the studies were small and two of them lacked a control group [37].

Iron supplementation (plus vitamin C) may be very effective when ferritin levels are below $10 \mathrm{ng} / \mathrm{ml}$. However, studies that correlate iron deficit with $\mathrm{BN}$ are rarely reported $[25,38]$.

Primary and secondary zinc deficiency is a cause of NF. Prolonged treatment with zinc $20-30 \mathrm{mg} /$ day seems to be effective in improving $\mathrm{BN}$ [38].

In a recent randomized trial, a biomineral formulation containing amino acids (L-cystine, L-arginine, glutamic acid), vitamins (C, E, B6 and biotin) and minerals (zinc, iron and copper) proved to be well tolerated and effective in strengthening and smoothing fingernails in subjects with onychoschizia after 3 months of treatment [39]. No data about dosage of the single elements is provided in the article [39].

In an open-label single-center trial, supplementation with "bioactive collagen peptides" was shown to be very effective in patients with BN after 24 weeks of treatment. In this study it was reported that nail growth rate increased by $12 \%$ and the frequency of broken nails decreased by $42 \%$ [40].

Nail moisturizers are useful in patients with BN. They may contain occlusive material (petrolatum or lanolin) and humectants (glycerin, propylene glycol and proteins). Alpha-hydroxy acids and urea may also be added to increase the water-binding capacity of the NP.
Several lacquers are commercially available to restructure nails affected by fragility. These products are known as nail hardeners, nail strengtheners, and fortifying nail builders, and may contain silicon. A new water-soluble nail strengthener specially formulated with a combination of active ingredients (silanediol salicylate and Pistacia lentiscus gum) that increase the quantity and quality of silicon and keratin in the nails. It contains cationic hyaluronic acid that adheres to the surface and deeply moisturizes the nails and cuticles. This combination of ingredients (patent pending) helps the natural process of nail growth. The safety and efficacy are supported by a 6-month clinical study [41].

A recent study observed that hydroxypropyl chitosan $(\mathrm{HPCH})$ nail lacquer when applied on the nails is useful to protect them against physical injuries, improving the nail structure [42]. The authors correlate the efficacy of $\mathrm{HPCH}$ to the high affinity with keratin that is secondary to water solubility without $\mathrm{pH}$ correction.

A second lacquer composed of $16 \%$ polyureaurethane could be used in $\mathrm{BN}$ to create a flexible waterproof barrier to environmental hazards [25]. The once daily application of both lacquers is recommended.

In a randomized controlled pilot study, the efficacy of topical cyclosporine emulsion (CsAE) versus emulsion (vehicle) alone have been compared. CsAE and also emulsion alone appeared to improve signs of brittle nails. Limitations of this study were the small sample size and the method for detection of efficacy [43].

These nail lacquers could increase the cosmetic outcomes of $\mathrm{BN}$, but further data are necessary to prove their true efficacy [44].

In recalcitrant fragility, nail wrapping limited to the distal portion of the nail may afford protection and camouflage. The procedure of nail wrapping consists of the application of layers of fibrous substances made of tissue paper, silk, linen, plastic film, or fiberglass on the distal edge of the NP to strengthen or repair its free edge. This same method is performed in artificial nails and sculptured nails and can considerably improve BN cosmetically. However, artificial nails could themselves be 
responsible for fragility because of the materials and procedures used to apply them $[45,46]$.

Good advice is to wear cotton gloves under vinyl gloves for wet work and heavy cotton gloves for dry work.

\section{CONCLUSIONS}

BN are a common complaint of patients presenting to a dermatologist. Before making a diagnosis of idiopathic $\mathrm{BN}$, secondary causes that might be responsible for $\mathrm{NB}$ should be investigated and excluded. Optimal management requires the treatment of the primary cause of $\mathrm{BN}$ when present, protective measures and bio-mineral supplementation. In addition, several products could be considered to reduce the physical and psychological impacts of this common problem, although double-blind, randomized controlled studies of such products are still lacking.

\section{ACKNOWLEDGEMENTS}

Funding. ISDIN provided funding to enable Bianca M. Piraccini to write to the article, no other funding was received for this study. The Rapid Service Fee was funded by the authors.

Authorship. All named authors meet the International Committee of Medical Journal Editors (ICMJE) criteria for authorship for this article, take responsibility for the integrity of the work as a whole, and have given their approval for this version to be published.

Disclosures. Marco A. Chessa, Matilde Iorizzo, Bertrand Richert, Jose L. López-Estebaranz, Dimitrios Rigopoulos, Antonella Tosti, Aditya K. Gupta, Nilton Di Chiacchio, Nilton G. Di Chiacchio, Adam I. Rubin, Robert Baran, Shari R. Lipner, Ralph Daniel, Soumya Chiheb, Chander Grover, Michela Starace, Bianca M. Piraccini have nothing to disclose.

Compliance with Ethics Guidelines. This article is based on previously conducted studies and does not contain any studies with human participants or animals performed by any of the authors.

Open Access. This article is distributed under the terms of the Creative Commons Attribution-NonCommercial 4.0 International License (http://creativecommons.org/licenses/ by-nc/4.0/), which permits any noncommercial use, distribution, and reproduction in any medium, provided you give appropriate credit to the original author(s) and the source, provide a link to the Creative Commons license, and indicate if changes were made.

\section{REFERENCES}

1. Lubach D, Cohrs W, Wurzinger R. Incidence of brittle nails. Dermatologica. 1986;172:144-7.

2. Scher RK. Brittle nails. Int J Dermatol. 1989;28: $515-6$.

3. Gequelim GC, Kubota CY, Sanches S, et al. Perception of brittle nails in dermatologic patients: a cross-sectional study. An Bras Dermatol. 2013;88: 1022-5.

4. Kechijian P. Brittle fingernails. Dermatol Clin. 1985;3:421-9.

5. Scher RK, Bodian AB. Brittle nails. Semin Dermatol. 1991;10:21-5.

6. Brosche T, Dressler A, Platt D. Age-associated changes in integral cholesterol and cholesterol sulfate concentrations in human scalp hair and fingernail clippings. Aging Clin Exp Res. 2001;13: $131-8$.

7. Duarte AF, Correia O, Baran R. Nail plate cohesion seems to be water independent. Int J Dermatol. 2009;48:193-5.

8. Stern DK, Diamantis S, Smith E, et al. Water content and other aspects of brittle versus normal fingernails. J Am Acad Dermatol. 2007;57:31-6.

9. Van de Kerkhof PC, Pasch MC, Scher RK, et al. Brittle nail syndrome: a pathogenesis-based approach with a proposed grading system. J Am Acad Dermatol. 2005;53:644-51. 
10. Uyttendaele H, Geyer A, Scher RK. Brittle nails: pathogenesis and treatment. J Drugs Dermatol. 2003;2:48-9.

11. Bardazzi F, Lambertini M, Chessa MA, Magnano M, Patrizi A, Piraccini BM. Nail involvement as a negative prognostic factor in biological therapy for psoriasis: a retrospective study. J Eur Acad Dermatol Venereol. 2017;31:843-6.

12. Tosti A, Piraccini BM, Cameli N. Nail changes in lichen planus may resemble those of yellow nail syndrome. Br J Dermatol. 2000;142:848-9.

13. Chessa MA, Alessandrini A, Starace M, et al. Erosive lichen planus: beyond the nails. J Eur Acad Dermatol Venereol. 2019;33:e97-9.

14. Kim M, Jung HY, Eun YS, Cho BK, Park HJ. Nail lichen striatus: report of seven cases and review of the literature. Int J Dermatol. 2015;54:1255-60.

15. Piraccini BM, Balestri R, Starace M, Rech G. Nail digital dermoscopy (onychoscopy) in the diagnosis of onychomycosis. J Eur Acad Dermatol Venereol. 2013;27:509-13.

16. Fustà X, Morgado-Carrasco D, Mascaró JM Jr. Image gallery: nail involvement in syphilis: the great forgotten. Br J Dermatol. 2017;177:e158.

17. Noriega L, Gioia Di Chiacchio N, Cury Rezende F, Di Chiacchio N. Periungual lesion due to secondary syphilis. Skin Appendage Disord. 2017;2:116-119.

18. Samman PD, Fenton DA. Samman's the nails in disease. In: 5th ed Oxford. Boston: ButterworthHeinemann; 1995.

19. Taguchi T. Brittle nails and hair loss in hypothyroidism. N Engl J Med. 2018;379:1363.

20. Geyer AS, Onumah N, Uyttendaele H, Scher RK. Modulation of linear nail growth to treat diseases of the nail. J Am Acad Dermatol. 2004;50:229-34.

21. Batory M, Namieciński P, Rotsztejn H. Evaluation of structural damage and $\mathrm{pH}$ of nail plates of hands after applying different methods of decorating. Int J Dermatol. 2019;58:311-8.

22. Zaias N. The nail in health and disease. 2 nd edn. Mc graw Hill Professional, 1992.

23. Weistenhöfer W, Uter W, Drexler H. Protection during production: problems due to prevention? Nail and skin condition after prolonged wearing of occlusive gloves. J Toxicol Environ Health A. 2017;80:396-404.

24. Dimitris R, Ralph D. Management of simple brittle nails. Dermatol Ther. 2012;25:569-73.
25. Iorizzo M. Tips to treat the 5 most common nail disorders: brittle nails, onycholysis, paronychia, psoriasis, onychomycosis. Dermatol Clin. 2015;33: $175-83$.

26. Almohanna HM, Ahmed AA, Tsatalis JP, Tosti A. The role of vitamins and minerals in hair loss: a review. Dermatol Ther (Heidelb). 2019;9:51-70.

27. Kitamori K, Kobayashi M, Akamatsu H, et al. Weakness in intercellular association of keratinocytes in severely brittle nails. Arch Histol Cytol. 2006;69:323-8.

28. Floersheim GL. Treatment of brittle fingernails with biotin. Z Hautkr. 1989;64:41-8.

29. Colombo VE, Gerber F, Bronhofer M, Floersheim GL. Treatment of brittle fingernails and onychoschizia with biotin: scanning electron microscopy. J Am Acad Dermatol. 1990;23(6 Pt 1): 1127-32.

30. Hochman LG, Scher RK, Meyerson MS. Brittle nails: response to daily biotin supplementation. Cutis. 1993;51:303-5.

31. Administration USFaD. Biotin (vitamin B7): Safety communication - may interfere 154 with lab tests. In: $11 / 28 / 2017$, ed.

32. Lipner SR. Rethinking biotin therapy for hair, nail, and skin disorders. J Am Acad Dermatol. 2018;78: 1236-8.

33. Maddy AJ, Tosti A. What's new in nail disorders. Dermatol Clin. 2019;37:143-7.

34. Williams GR, Cervinski MA, Nerenz RD. Assessment of biotin interference with qualitative point-of-care hCG test devices. Clin Biochem. 2018;53:168-70.

35. John JJ, Cooley V, Lipner SR. Assessment of biotin supplementation among patients in an outpatient dermatology clinic. J Am Acad Dermatol. 2019;81: 620-1.

36. James K, Sara PO, Sarah S et al. The effect of a combination of an arginine silicate complex and magnesium biotinate on hair and nail growth in rats (P06-026-19). Curr Dev Nutr. 2019;3:nzz031. P06-026-19.

37. Lipner SR, Scher RK. Biotin for the treatment of nail disease: what is the evidence? J Dermatol Treat. 2018;29:411-4.

38. Di Baise M, Tarleton SM. Hair, nails, and skin: differentiating cutaneous manifestations of micronutrient deficiency. Nutr Clin Pract. 2019;34:490-503. 
39. Sparavigna A, Tenconi B, La Penna L. Efficacy and tolerability of a biomineral formulation for treatment of onychoschizia: a randomized trial. Clin Cosmet Investig Dermatol. 2019;13(12):355-62.

40. Hexsel D, Zague V, Schunck M, Siega C, Camozzato FO, Oesser S. Oral supplementation with specific bioactive collagen peptides improves nail growth and reduces symptoms of brittle nails. J Cosmet Dermatol. 2017;16:520-6.

41. Starace M, Alessandrini A, Bruni F, Brandi N, Piraccini BM. An open clinical investigation on clinically and dermoscopically visible effects of application of a topical product for 6 months on brittle nails and weak nails with rough surface and/ or tendency to break. Poster presented at the 24th Word Congress of Dermatology, Milan, 10-15 June 2019.
42. Sparavigna A, Caserini M, Tenconi B, et al. Effects of a novel nail lacquer based on hydroxypropyl-chitosan $(\mathrm{HPCH})$ in subjects with fingernail onychoschizia. J Dermatol Clin Res. 2014;2:1013-8.

43. Mackay-Wiggan J, Marji J, Walt JG, et al. Topical cyclosporine versus emulsion vehicle for the treatment of brittle nails: a randomized controlled pilot study. J Drugs Dermatol. 2014;13:1232-9.

44. Iorizzo M, Piraccini BM, Tosti A. Nail cosmetics in nail disorders. J Cosmet Dermatol. 2007;6:53-8.

45. Baran R, André J. Side effects of nail cosmetics. J Cosmet Dermatol. 2005;4:204-9.

46. Dahdah MJ, Scher RK. Nail diseases related to nail cosmetics. Dermatol Clin. 2006;24(233-9):vii. 